\title{
Genotoxicity induced by drug-drug interaction between the antidepressant sertraline and the antibiotic erythromycin in mice bone marrow cells.
}

\author{
Amany A. Tohamy \\ Zoology Department, Faculty of science, Helwan University
}

\begin{abstract}
Drug-drug interaction represents a widely distributed health problem. The pharmacological action and side effects of two or more drugs can act additively or antagonistically. The present study was designed to evaluate the possible genotoxicity of concurrent treatment with the antidepressant sertraline, one of the serotonin reuptake inhibitors (SSRI) and the broad spectrum macrolide antibiotic erythromycin.

Sertraline and erythromycin are metabolized through CYP3A4 which is one of the cytochrome P-450 enzymes in liver and are responsible for the metabolism of large number of endogenous substrates and therapeutic agents.

The frequency of micronucleated polychromatic erythrocytes (MNPCEs), micronucleated normochromatic erythrocytes (MNNCEs) and the ratio PCE/NCE were evaluated to measure the genotoxicity of separate and combined treatment with the tested two drugs.

Clinical doses of both sertraline $(0.71 \mathrm{mg} / \mathrm{kg}$ b.w.) and erythromcyin strearate $(14.30 \mathrm{mg} /$ $\mathrm{kg}$ b.w.) were used. Groups of animals received single separate or combined doses of either sertraline and/or erythromycin, and sacrificed after 24 hours. Other groups of mice were treated in the same way but for five consecutive days and sacrificed 24 hours after the last injection. In all treated groups, the percentage of PCEs increased significantly when compared with that of the negative control group which may indicate a stimulation of proliferative activity to an early phase of cell depletion. The genotoxicity of multiple treatment for 5 consecutive days with sertraline alone or in combination with erythromcyin was expressed in increased number of MNPCEs.

The observed increased genotoxicity after multiple combined treatment with sertraline and erythromycin may indicate increased risk of toxicity-based drug-drug interaction. This toxicity may be due to the ability of sertraline and erythromycin to inhibit the activity of CYP3A4 which lead to a prolonged storage period of drugs in the body and hence increased toxicity.
\end{abstract}

Key words : Genotoxicity, Drug-drug interaction, Sertraline, Erythromycin

\section{Introduction}

Drug-drug interactions represent a widely distributed health problem and are divided into pharmacodynamic (PD) and pharmacokinetic (PK) interactions. PD drug-drug interactions can change the pharmacological effect of drugs.

Furthermore, the pharmacological effect and side effects of two or more drugs can act additively or antagonistically. PK drug-drug interactions are associated with inappropriate plasma concentrations of drugs which can be the result of inadequate absorption, transport, metabolism or elimination (Piscitelli and Grallicano, 2001).
The selective serotonin reuptake inhibitors (SSRIs) have become the most frequency prescribed antidepressants. These medicines are thought to work by increasing the activity of certain chemical, called serotonin, in the brain (Hemeryck and Belpaire, 2002).

Sertraline is one of the SSRIs and is marketed in Egypt under the trade name Lustral (Pfizer, Egypt). Sertraline is used to treat mental depression, obsessivecompulsive disorder and panic disorder (Murdoch and Mc-Tavish, 1992). Henry et al. (2004) stated that sertraline is 
considered the most toxic SSRIs. However, in a genetic toxicity study performed by the manufacturer of the drug (Pfizer, USA), Davis and Klowe (1998) concluded that sertraline was not genotoxic in an extensive battery of tests.

Erythromycin stearate is a broadspectrum macrolide antibiotic widely used in humans. The macrolide antibiotics working by blocking the entrance to the tunnel in the large ribosomal subunit through which nascent peptide chains exit the ribosome. Blocking of the exit tunnel by macrolides induces premature dissociation of peptidyl-tRNAs from the ribosome (Tenson et al., 2003).

According to the few available studies, it was concluded that erythromycin has no mutagenic properties (National toxicology program, 1988 and Isidori et al., 2005).

Cytochrome P-450 3A4 (CYP3A4) is one of the cytochrome P-450 enzymes in liver and is responsible for the metabolism of a large number of endogenous substrates and therapeutic agents (Wang et al.,2000). Among the therapeutic agents metabolized through CYP3A4 is sertraline (Murdoch and McTavish, 1992) and erythromycin (Wang et al., 1997). Wang et al. (2000) concluded that the possibility of metabolism-based drug interaction exists if drugs are metabolized by the same cytochrome P-450.

The present study was designed to evaluate the adverse effects of concurrent treatment with sertraline and erythromycin. Micronucleus test using in vivo mammalian system was conducted as a measure for genotoxicity of the tested drugs under the experimental conditions used in the present study.

\section{Materials and Methods}

(1) Chemicals

a-Antidepressant :

Lustral is the trade name of the medical product sertraline. The drug is manufactured by Pfizer Egypt S.A.E., Cairo, A.R.E., under authority of Pfizer
I.N.C., USA, in the form of tablets containing $50 \mathrm{mg}$ sertraline each.

\section{b-Antibiotic}

Erythromycin is the trade name of the erythromycin strearate. It is produced by strain of Streptomyces erythraeus and belongs to the macrolide group of antibiotics. It is basic and readily forms salts with acids. Erythromycin strearate is produced by Kahira Pharm. and chem.. Ind. Com. Under license from ABBOTT Laboratories, North Chicago, Illinois, USA, in the form of tablets contain $250 \mathrm{mg}$ erythromycin strearate each.

\section{(2) Animals and treatment :}

Ten-weeks-old male Swiss mice each weighing 20-25 $\mathrm{gm}$ were used in the present study as the experimental animals. The animals were housed at room temperature and given diet and water $a d$ Libitum. The animals were divided into two groups (A and B) of 15 mice each. Each group was subdivided into three subgroups of 5 animals each and treated as follows:

\section{Group A :}

The animals received single separate or combined intraperitoneal injection of the clinical doses of either sertraline $(0.71 \mathrm{mg} /$ $\mathrm{kg}$ b.w.) or/and erythromycin $(14.3 \mathrm{mg} / \mathrm{kg}$ b.w.). The animals were sacrificed $24 \mathrm{hr}$ after treatment.

\section{Group B :}

The animals received separate or combined intraperitoneal injections for 5 consecutive days of the clinical doses of either sertraline or/and erythromycin. The animals were sacrificed $24 \mathrm{hr}$ after the last injection.

One group of 5 animals was used as negative untreated control.

\section{(3) Micronucleus analysis :}

Bone marrow smears were prepared and allowed to dry overnight. Differential staining to distinguish PCEs and NCEs with May-Grunwald and Giemsa stains was performed (Schmid, 1976). A total of 1000 polychromatic erythrocytes (PCEs) were examined and number of micronucleated PCEs (MNPCEs) were recorded for each individual mice using $100 \mathrm{x}$ (oil 


\section{Amany A. Tohamy}

immersion). The number of normochromatic erythrocytes (NCEs) was also counted in the fields of recorded PCEs and scored for MN. The PCEs/ NCEs ratio was also counted and expressed as \% PCEs.

\section{(4) Statistical analysis :}

Mann-Whitney test was applied for the statistical analysis of the data obtained.

\section{Results}

Table 1 and figure 1 show that single treatment with the clinical doses of either the antibiotic erythromycin ( $14.3 \mathrm{mg} / \mathrm{kg}$ b.w.) or the antidepressant sertraline hydrochloride ( $0.71 \mathrm{mg} / \mathrm{kg}$ b.w.) induced slight and statistically non significant increase in the number of micronucleated polychromatic erythrocytes (MNPCEs) when compared with that of the control group. Moreover, single combined treatment with erythromycin and sertraline gave the same result.

Multiple treatment (for 5 consecutive days) with the clinical dose of erythromycin did not affect the number of MNPCEs in mice bone Marrow cells. On the other hand, a significant increase in the number of MNPCEs (at $\mathrm{P}<0.05$ ) from the - ve control level was recorded after multiple treatment with the clinical dose of the antidepressant sertraline. Also, combined treatment with erythromycin and sertraline for 5 consecutive days resulted in a statistically significant increase (at $\mathrm{P}<$ 0.05 ) in MNPCEs when compared with the -ve control level.

When comparing the effects of separate treatment with that of combined treatment, the number of MNPCEs increased significantly only after multiple combined treatment with the two drugs.

No significant difference was recorded in the number of MNNCEs between the different studied groups.

The percent polychromatic erythrocytes (\%PCEs) increased significantly (at $\mathrm{P}<0.05)$ in all treated groups when compared with that of the -ve control group (table 1 and fig. 2).

Table 1 : Frequencies of MNPCEs and MNNCEs in mice bone marrow cells after single or combined treatment with erythromycin and/or sertraline.

\begin{tabular}{|c|c|c|c|c|c|}
\hline \multirow[t]{2}{*}{ Group } & \multirow[t]{2}{*}{ Treatment } & \multirow{2}{*}{$\begin{array}{l}\text { Dose } \quad(\mathrm{mg} / \\
\mathrm{kg})\end{array}$} & \multicolumn{2}{|c|}{ Mean / animal \pm SD } & \multirow{2}{*}{$\begin{array}{l}\% \text { PCEs (Mean / } \\
\text { animal } \pm \mathrm{SD})\end{array}$} \\
\hline & & & MNPCEs & MNNCEs & \\
\hline 1 & -ve control & - & $1.0 \pm 0.71$ & $0.2 \pm 0.45$ & $61.24 \pm 2.11$ \\
\hline 2 & Sertraline $(\mathrm{S})$ (Single) & 0.71 & $1.2 \pm 0.84^{\mathrm{e}}$ & $0.0 \pm 0.00$ & $68.92 \pm 3.95^{\mathrm{a}, \mathrm{b}, \mathrm{c}}$ \\
\hline 3 & Erythromycin (E) (Single) & 14.30 & $2.0 \pm 2.00^{\mathrm{d}}$ & $0.2 \pm 0.45$ & $83.06 \pm 2.45^{\mathrm{a}}$ \\
\hline 4 & $\mathrm{E}+\mathrm{S}$ (Single) & $14.30+0.71$ & $2.0 \pm 1.58^{f}$ & $0.4 \pm 0.55$ & $83.00 \pm 2.36^{\mathrm{a}, \mathrm{f}}$ \\
\hline 5 & Sertraline (S) (Multiple) & 0.71 & $4.2 \pm 2.28^{\mathrm{a}, \mathrm{c}}$ & $0.2 \pm 0.45$ & $76.34 \pm 2.96^{\mathrm{a}, \mathrm{c}}$ \\
\hline 6 & Erythromycin (E) (Multiple) & 14.30 & $0.2 \pm 0.45^{\mathrm{c}}$ & $0.0 \pm 0.00$ & $77.59 \pm 2.98^{\mathrm{a}, \mathrm{c}}$ \\
\hline 7 & $\mathrm{E}+\mathrm{S}$ (Multiple) & $14.30+0.71$ & $8.0 \pm 1.58^{\mathrm{a}}$ & $0.2 \pm 0.45$ & $89.10 \pm 1.85^{\mathrm{a}}$ \\
\hline
\end{tabular}

a : Significant difference from group 1 at $\mathrm{P}<0.05$

$\mathrm{b}$ : Significant difference from group 4 at $\mathrm{P}<0.05$

c : Significant difference from group 7 at $\mathrm{P}<0.05$

$\mathrm{d}$ : Significant difference from group 6 at $\mathrm{P}<0.05$

e : Significant difference from group 5 at $\mathrm{P}<0.05$

$\mathrm{f}$ : Significant difference from group 7 at $\mathrm{P}<0.05$ 

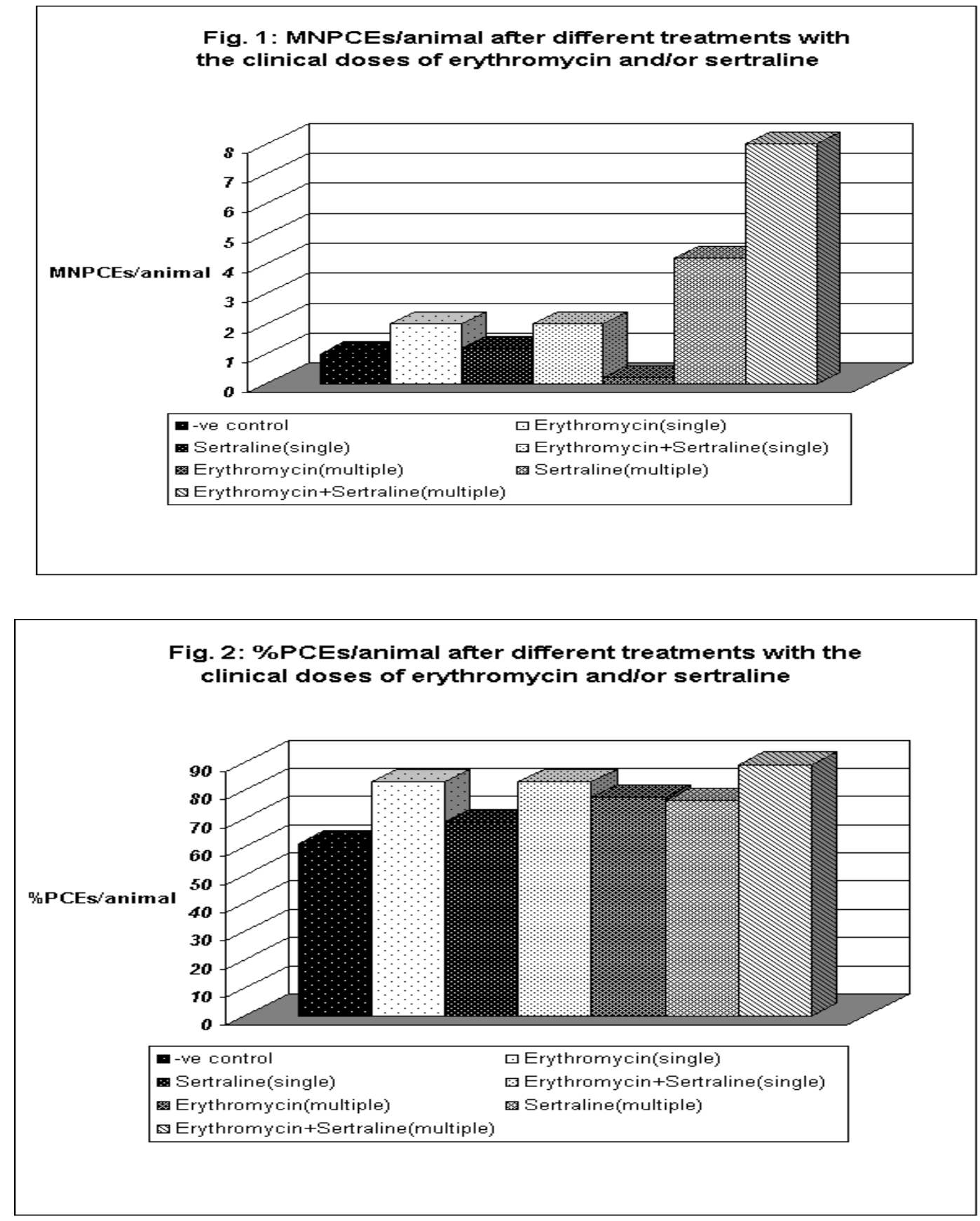

\section{Discussion}

Because many patients require longterm maintenance treatment with antidepressant, the SSRIs such as sertraline, are frequently co-prescribed with other medications which may lead to clinically important interactions (Hemeryck and Belpaire, 2002).
In the present study, the number of MNPCEs increased significantly only after multiple treatment with the antidepressant sertraline alone and concurrently with the antibiotic erythromycin. In all treated groups, the \% PCEs increased significantly when compared with that of the negative 
control group which may indicate a stimulation of proliferative activity due to an early phase of cell depletion (Adler et al., 1991).

The observed genotoxicity of multiple treatment for 5 consecutive days with sertraline seems to contradict the results of genetic toxicity study performed by the manufacturer of sertraline (Pfizer, USA) and concluded that sertraline was not genotoxic in an extensive battery of tests (Davis and Klowe, 1998). However, the rare literature data regarding genotoxicity of sertraline and its widespread use for long periods of time, in addition to its genotoxic activity in the present study, focus attention on the need for more studies on the genotoxicity of sertraline and other long term used antidepressants.

The non-genotoxic effect of single or multiple treatments with erythromycin, observed in the present study, supports the previous conclusion that erythromycin has no mutagenic properties (National Toxicology Program, 1988 and Isidori et al., 2005)

In the present work, the observed increased genotoxicity of the multiple combined treatment with the SSRI sertraline and erythromycin may indicate increased risk of toxicity-based drug-drug interaction. N-demethylation of sertraline and erythromycin is the main metabolic pathway in their biotransformation and correlates with the activity of the same cytochrome P-450 isoform (CYP3A4) (Wang et al, 1997; and Hemeryck and Belpaire, 2002). Accordingly, the two drugs will compete for the same enzyme catalytic site which may lead to displacement of either medication from protein-binding sites leading to increased plasma concentration of the free (unbound) medications and increased risk of adverse effects (Sertraline package insert, 1997 and sertraline product monograph, 1997).

Moreover, the reported ability of both sertraline and erythromycin, to inhibit the activity of CYP3A4 (Dresser et al., 2000; Hemeryck and Belpaire, 2002 and Ulrich, 2002) may offer another explanation for the observed increased genotoxicity of combined treatment with the two drugs.
Inhibition of CYP3A4 activity will lead to a prolonged storage period of drug in the body and hence increased toxicity.

\section{References}

1. Adler, I.D., Kliesch, U., Helmmelen, P. Van and Kirch Volders. M, 1991: Mouse micronucleus test with known and suspect spindle poisons. Results from two laboratories. Mutagenesis, $6: 47-53$

2. Davis, T.S. and Klowe, W.M. 1998: Preclinical toxicological evaluation of sertraline hydrochloride. Drug Chem.. Toxicol., 21 (2) : 163 - 179.

3. Dresser, G. K., Spence, J.D. and Dialey, D.G. 2000: Pharmacokinetic Pharmadynamic Consequences and Clinical Relevance of Cytochrome P-450 3A4 Inhibition. Clinical pharmacokinetics, 38 (1) : $41-57$.

4. Hemeryck, A. and Belpaire, F.M. 2002 : Selective Serotonin Reuptake Inhibitors and Cytochrome P-450 Mediated Drug-Drug Interactions : An Update. Current Drug Metabolism, $3: 13-37$.

5. Henry, T.B.; Kwon, J.; Armbrust, K.L. and Black, M.C. 2004: Acute and chronic toxicity of five selective serotonin reuptake inhibitors in Ceriodaphnia dubia. Environ. Toxicol. Chem., 23 : 2229-2233.

6. Isidori, M.; Lavorgna, M.; Nardelli, A.; Pascarella, L. and Parrella, A. 2005 : Toxic and genotoxic evaluation of six antibiotics on non-target organisms. Soc. Total Environ., 15, 346 (1-3) : 87-98.

7. Murdoch, D. and McTavish, D. 1992: Sertraline : a review of its pharmacodynamic and pharmacokinetic properties, and therapeutic potential in depression and obsessive - compulsive disorder. Drugs, 44 (4) : $604-624$.

8. National toxicology program. 1988: NTP Toxicology and carcinogenesis studies of Erythromycin stearate (CAS NO. 643-22-1) in F344/ N Rats and B6C3F1 Mice (Feed Studies). National Toxicology program Tech. Rep. Ser.: 338 : 1-167.

9. Piscitelli, S.P. and Grallicano, K.D., 2001: Interaction among drugs for HIV and opportunistic informations. N. Engl. J. Med., 344 : 984 - 966.

10. Schmid, W., 1976: The micronucleus test for cytogenetic analysis, in : A. Hollander (Ed.), Chemical Mutagens. Principles and Methodes for their detections 4, Plenum, New York, pp. 31-53. 
11. Sertraline package insert (Zoloft, PfizerUS), Rev 10/97, Rec 11/97.

12. Sertraline product monograph (Zoloft, Pfizer-Canada), Rev 12/19/96, Rec 1/23/97.

13. Tenson, T.; Lovmar, M. and Ehrenberg, M. 2003: The mechanism of action of macrolides, lincosamides and streptogramin $B$ reveals the nascent peptide exit path in the ribosome. J. Mol. Biol., 330 : 10051014.

14. Ulrich, K. 2002: Interaction Potential of lercamidipine, a new vasoselective dihydropyridine calcium antagonist. Arzneim. Forsch., 52(3) : 155-161.
15. Wang, R.W.; Debroah, J.; Newton, N. L.; William, M.; Atkins, M. and Anthony Y.H. 2000 : Human cytochrome P-450 3A4 : In vitro drug-drug interaction patterns are substrate - dependent. Drug Metabolism and Disposition, 28(3) : 360-366.

16. Wang, R.W.; Newton, D.J.; Scheri, T.D. and Lu, A.Y.H. 1997: Human cytochrome P-450 3A4-catalyzed testosterone 6Bhydroxylation and erythromycin $\mathrm{N}$-demethylation : completion during catalysis. Drug Metabolism and disposition, 25 : 502 $-507$. 


\section{السمية الوراثية الناتجة عن تفاعل عقار مع عقار بين مضاد الاكتئاب

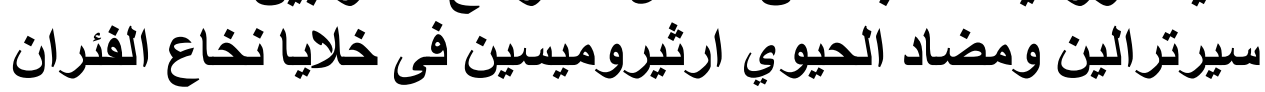

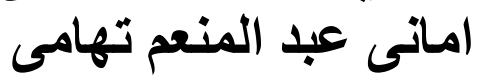 جامعة حلو ان - كلية العلوم ـقسم علم المئم الحيوان}

يمثل التفاعل بين عقار و عقار مشكلة صحية و اسعة الانتشـار ـ ويمكن للأثر الدوائي

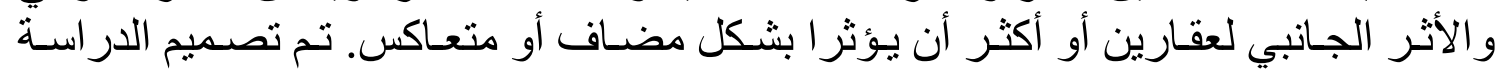

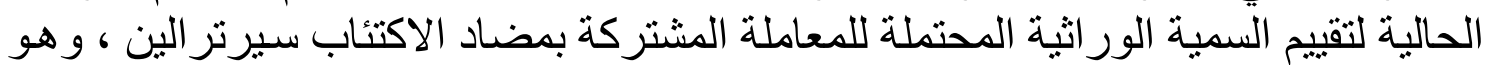

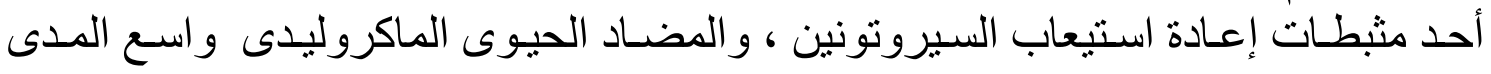

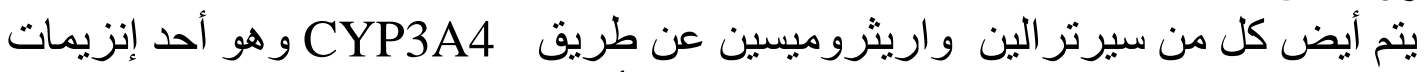

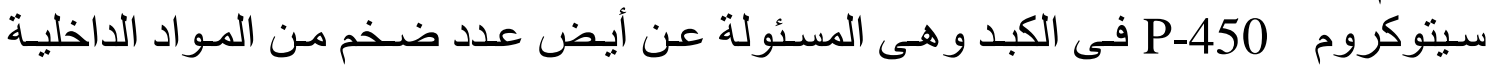

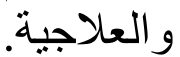

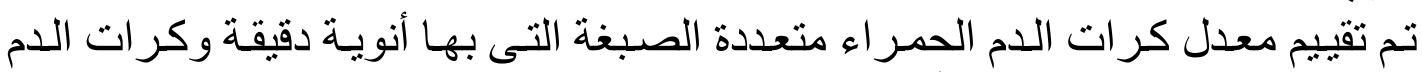

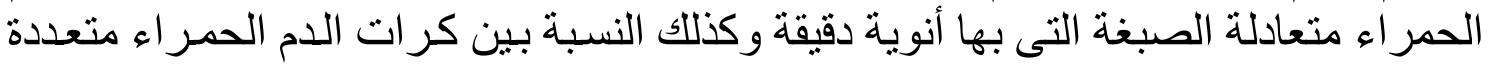

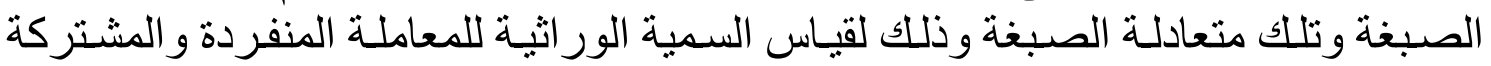
بالعقارين موضع الدار ماسة.

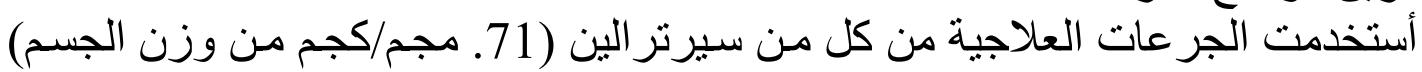

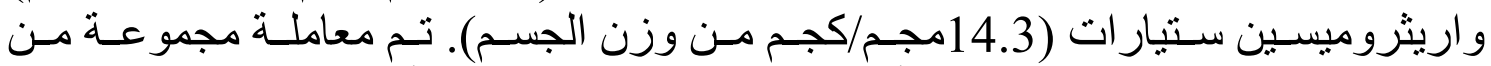

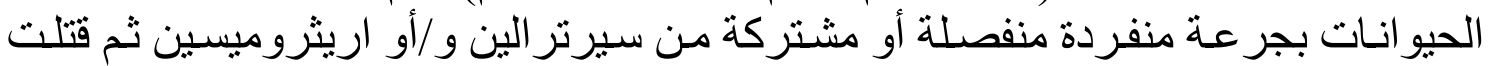

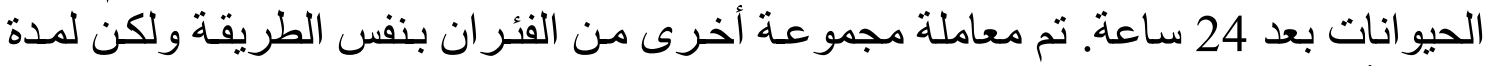

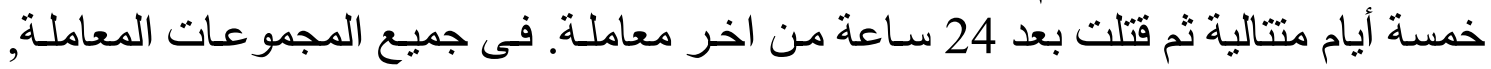

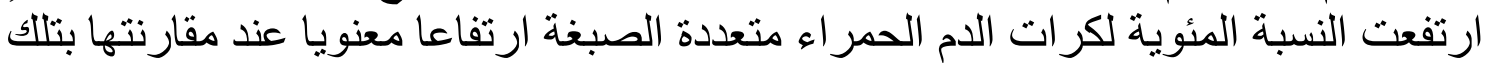

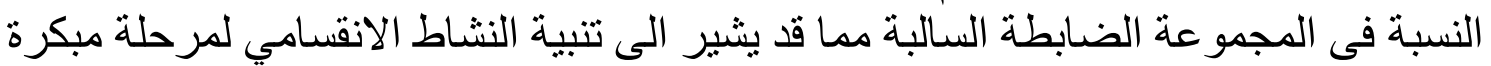

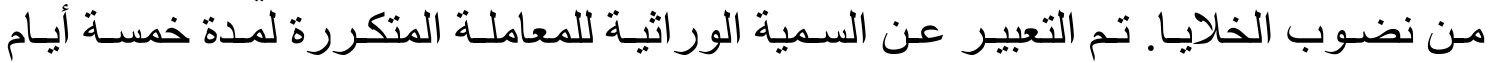

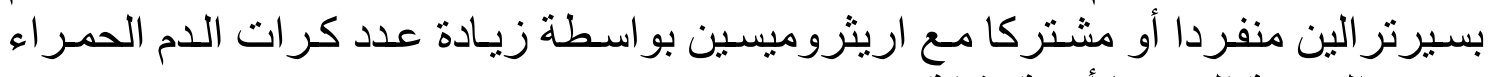
متعددة الصبغة التي بها أنوية دقيقة.

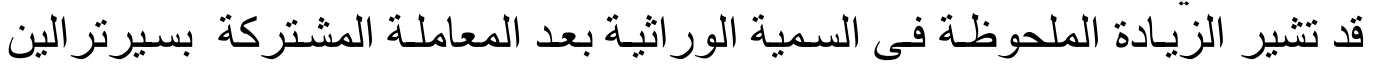

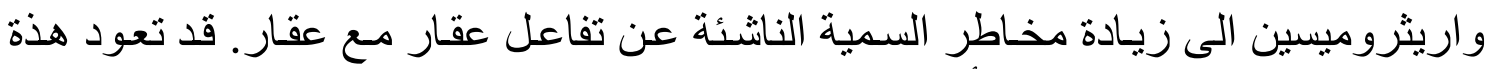

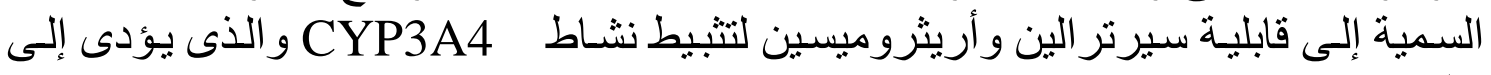
إطالة فترة مكوث العقاقير فى الجسم وبالتالي زيادة سميتها. 